\title{
Autophagy and Its Implication in Antiviral Immunity
}

\author{
Houda Khatif and Ingo Drexler* \\ Institute for Virology, University of Düsseldorf, Universitätsstr.1, 40225, Düsseldorf, Germany
}

Received: October 06, 2014; Accepted: November 11, 2014; Published: November 23, 2014

*Corresponding author: Ingo Drexler, Institute for Virology, University of Düsseldorf, Universitätsstr.1, 40225, Düsseldorf, Germany, Tel: + 49-(0)211-811-2781, E-mail: ingo.drexler@med.uni-duesseldorf.de

\begin{abstract}
Autophagy is a catabolic mechanism developed in eukaryotes in order to maintain cellular homeostasis and development. It is also an essential constituent of the immune system since it is involved in the MHC class I and II antigen generation and exerts an antiviral effect. However many viruses are either able to inhibit or induce autophagy to avoid their own elimination or to favor their replication by interacting with different complexes of the autophagy pathway. This review summarizes the molecular mechanisms of autophagy and its importance in immunity. It describes the different strategies that viruses have adopted to hijack this process.
\end{abstract}

Keywords: Autophagy; Antigen processing and presentation; MHC Class I and II; CD4 ${ }^{+}$T cells; Viral infection; Immune evasion

\section{Introduction}

Extracellular antigens are taken up through endocytosis Activation of specific proteases leads to acidification of endosomal vesicles and degradation of exogenous proteins into peptides. Contrary to micro- or chaperone mediated autophagy, where the substrates are directly delivered to lysosomes for degradation, macroautophagy (hereafter referred to as autophagy) is divided into different phases starting with the formation of autophagosomes, generated from a pre-autophagosomal structure known as phagophore. Autophagosomes were detected in the late 1950's for the first time in mammalian cells through electron microscopy $[1,2]$. They belong to double-membrane vesicles that are responsible for the sequestration of cytosolic components, including damaged organelles, polyubiquitinated protein aggregates and pathogens [3]. Their fusion with lysosomes contributes to the formation of autolysosomes, which promote cargo degradation and vesicle break-down conducted by acidic hydrolases (Figure 1). Autophagy is also defined as a process which occurs in eukaryotic cells, and can either be induced or inhibited to maintain tissue homeostasis and development. However, since defective autophagy is associated with numerous diseases such as chronic inflammatory diseases (e.g. neurodegenerative or pulmonary diseases) or cancer, it plays an essential role in immunity [4]. For this reason, pathogens and especially viruses have developed specific mechanisms to inhibit autophagy or to take advantage from this machinery for their own replication and by this way to manipulate or evade the immune system.

\section{Molecular Regulation of Autophagy}

Autophagy was originally identified by Ashford and Porter in rat hepatocytes and described to be a cellular response to starvation [5]. Autophagy-related genes (Atgs), which were actually identified in yeast, are conserved in eukaryotic cells and participate in autophagosome formation [6-8]. Energy depletion, starvation or infection, are responsible for activation of autophagy, which involves the induction of a highly sophisticated signaling cascade initiated by the AMP- Activated Protein Kinase (AMPK)mediated stimulation of the ULK1:Atg13:FIP200 complex as described below [4]. In the presence of growth or nutrient factors like insulin or amino acids, mammalian Target of Rapamycin (mTOR) is stimulated and autophagosome formation is disabled [Figure2] [9]. mTOR is a $280 \mathrm{kDa}$ large Ser/Thr protein kinase, which is implicated into cellular metabolism regulation [10]. mTOR resides in two complexes mTORC1 and mTORC2 [11]. mTORC2 is rapamycin insensitive and mainly responsible for the rearrangement of actin cytoskeleton [12]. On the other hand, mTORC1 is rapamycin sensitive and constituted of mTOR, The G protein beta subunit-like protein $(\mathrm{G} \beta \mathrm{L})$, the regulatory associated protein of mTOR (raptor) and the Proline-Rich Akt/PKB substrate $40 \mathrm{kDa}$ (PRAS40). It monitors protein synthesis, nutrient import and Autophagy $[10,11,13,14]$. mTORC1 activation is controlled by the class I Phosphatidylinositol 3-Kinase (PI3K)-AKT pathway through perception of growth factors $[13,15]$. In the case of energy deprivation and ATP decrease, mTORC1 blockage is mediated via AMPK to stimulate autophagy [15]. Autophagy is triggered by stimulating the ULK1:Atg13:FIP200 complex through inhibition of mTOR [16-18]. The Unc- 51-like Kinase (ULK)-1 and the 200 $\mathrm{kDa}$ focal adhesion kinase family- interacting protein (FIP200) interact with Atg13, which in turn is stabilized by the expression of Atg101 [11,19,20]. Phagophore nucleation and assembly necessitate the initiation of the PI3K complex, composed of the class III PI3K, the regulatory protein kinase p150, Beclin 1 and Atg14L, a Beclin 1-associated key regulator [21,22]. This results in the production of Phosphatidylinositol-3-Phosphate (PI3P), which enables autophagosome formation (Figure 2).

Vesicle elongation is promoted by two ubiquitin-like conjugation systems [9]. For the first system, Atg12 is activated 


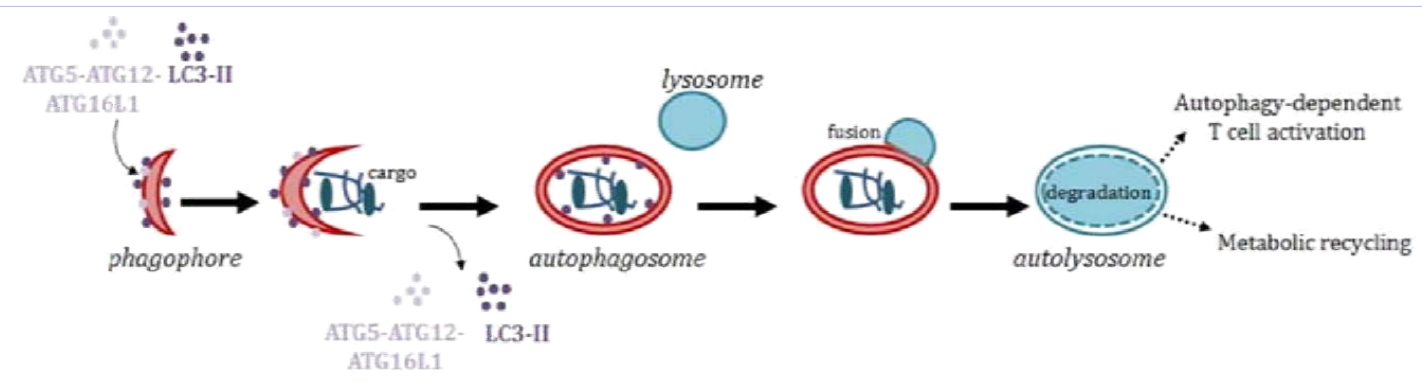

Figure 1: The different steps of Autophagy: Autophagosomes develop from a pre-structure called phagophore. Through vesicle elongation, the cargo is sequestered by the autophagosome and degraded after autolysosome formation. The components are either released or used for recycling or may serve as peptides for MHC class II antigen presentation [4].

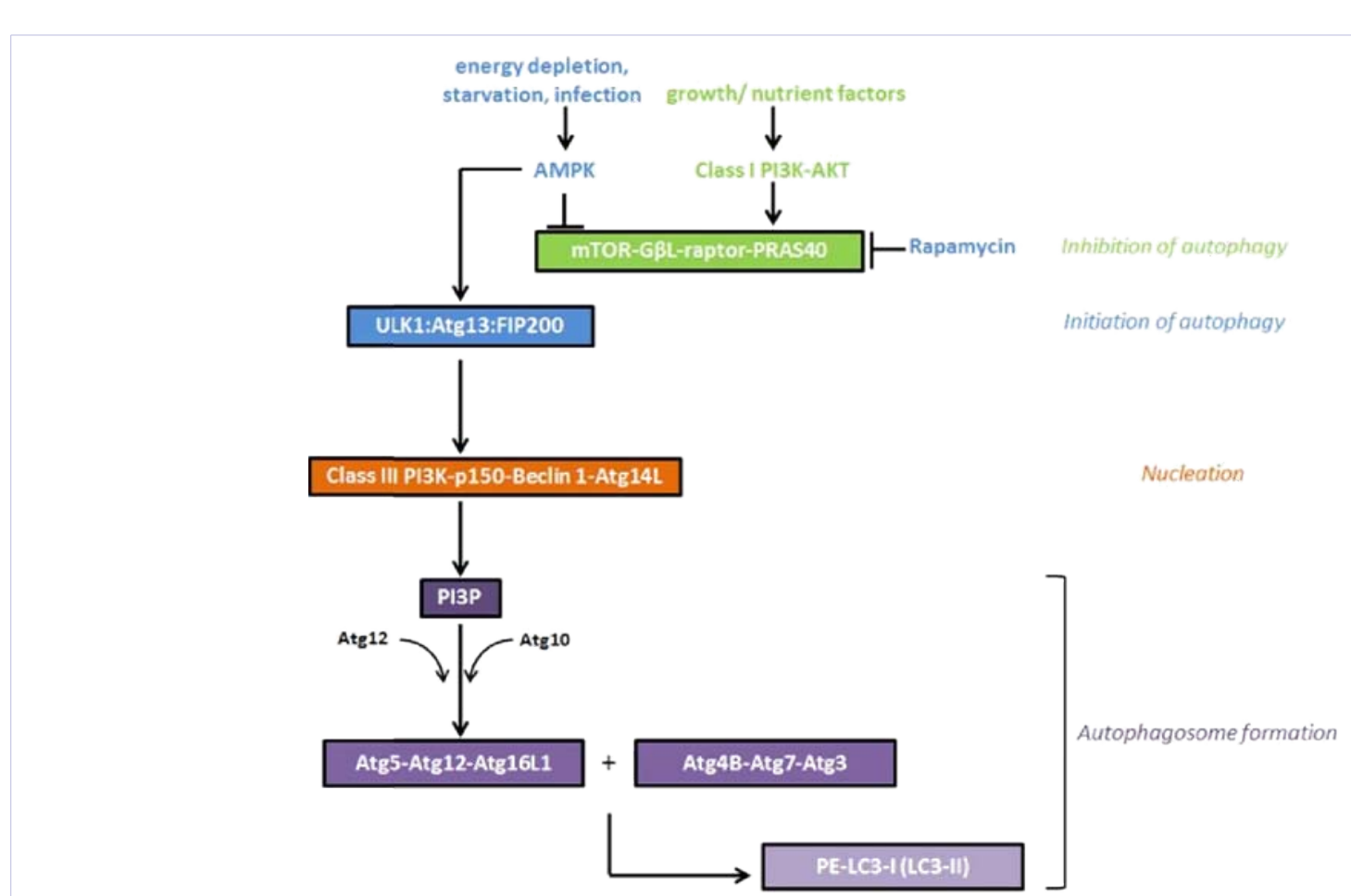

Figure 2: Activating signaling cascade for Autophagy: Autophagy can be induced or inhibited bydiverse factors. In the case of induction, different complexes are triggered leading to final autophagosome formation. However, inhibition of autophagy is mediated by activation of the mTOR complex.

by the E1-like enzyme Atg7 and conjugation of Atg12 to Atg5 is sustained by the E2-like enzyme Atg10. Binding of Atg16L1 to Atg5-Atg12, which exhibits an E3-like enzyme activity, contributes to the generation of a heterotrimeric complex, located at the phagophore membrane. This complex, together with the Atg4B protease, Atg7 and Atg3, encompass the second ubiquitin-like conjugation system, which establishes the interaction between phosphatidyl Ethanolamine (PE) and the microtubule- associated protein light chain 3 (LC3-I, mammalian homolog of Atg8). The conversion of LC3-I to the lipidated and membrane-associated form LC3-II (PE conjugated) is a common marker and regulator for autophagosome formation that directs further steps of Autophagy [9].

After fusion of lysosome with autophagosome, specific acidic hydrolases are released inside of the autolysosome, leading to cargo degradation and finally to vesicle breakdown for metabolic recycling (Figure 1). Previous investigations demonstrated that autophagy is strongly implicated into the adaptive immune response especially in the generation of Major Histocompatibility Complex (MHC) class II restricted antigens [23-25] but can also be involved in innate immunity and generation of MHC class I peptides as described below.

\section{Autophagy-Related MHC class I and II Peptide Generation}

Infectious, pathogen-derived antigens are presented by MHC class I or II molecules to surveilling T-cells.Contrary to MHC class I molecules, which are expressed on all nucleated cells, MHC class II is only found on professional Antigen Presenting Cells (APCs) like Dendritic Cells (DCs), B-cells, macrophages and certain epithelial cells. Additionally, MHC class I antigens are from cytosolic origin 
and processed by proteasomes to be translocated into the endoplasmic reticulum (ER) via the Transporter Associated with antigen Processing (TAP) [26]. However MHC class I peptides can also be generated through Autophagy. This was firstly shown by English et al. in the context of HSV-1 infected macrophages [27], which identified the implication of a vacuolar pathway in the generation of endogenous MHC class I antigens for $\mathrm{CD}^{+} \mathrm{T}$-cell stimulation. Although this process differs in some aspects from the conventional macroautophagy, e.g. detection of two and four layered membrane structures, accumulation of LC3 molecules and the dependence on Atg5 at 6-8 hours post infection revealed the existence of a connection between autophagy and MHC class I antigen presentation [27]. An alternative autophagy-mediated endogenous MHC class I peptide presentation was characterized as being TAP-independent and implied the use of a vacuolar pathway. This was described for the Human Cytomegalovirus (HCMV) - encoded pUL138 protein, which can either be generated by the conventional route or through lysosomal proteases [28]. MHC class I molecules are also known to present extracellular antigens in APCs to CD8 ${ }^{+}$T-cells via cross-presentation [29]. In line with this, knockdown of specific Atgs (e.g. Beclin-1 and Atg12) in tumor cells caused a significant decrease in crosspresentation. This assumes the dependence of cross-presentation on autophagy, playing an essential role in antigen delivery to DCs, although the exact mechanism is not completely understood [30].

Regarding MHC class II antigens, they are mainly generated from exogenous proteins $[31,32]$ but can also be from nuclear and cytosolic origin if processed through Autophagy [31,33]. In support of this notion, 20-30\% of natural MHC class II ligands turned out to be derived from endogenous proteins produced through Autophagy [2,23,34]. To provide efficient antigen presentation, the MHC class II $\alpha$ - and $\beta$-chain assemble in the ER and interfere with the invariant chain (Ii), to prevent the binding of premature epitopes. Thus, this complex is transported to the acidic endosomal MHC class II compartment (MIIC) within APCs, where Ii is digested, leaving a class II associated Ii peptide (CLIP). The binding of MHC class II antigens is mediated by HLA-DR, being responsible for the dissociation of CLIP from the peptide binding groove. Antigens generated via autophagy are delivered to MHC class II molecules through direct fusion of autophagosomes with MIIC, or with endosomes which then in turn merge with MIIC [35,36]. A recent study posits the existence of endosomemediated autophagy in DCs, characterized by the formation of MIIC-derived autophagosomes [37], which supplementary confirms the relationship between autophagy and MHC class II antigen presentation. Hence, the MHC class II complex is released from MIIC and peptides are presented to $\mathrm{CD} 4^{+} \mathrm{T}$ - cells [Figure 3] [31].

\section{Autophagy in Innate and Adaptive Immunity}

In case of an infection, it's is well known that APC activation is conducted through binding of pathogens to Pattern-Recognition Receptors (PRRs) which are subdivided into different classes, comprising the membrane-bound Toll- like Receptors (TLRs). TLRs recognize microbial patterns to induce an innate immune response which is initially implemented by a downstream signaling cascade, including the adaptor molecules myeloid differentiation primary-response protein 88 (MyD88) and TIR domain-containing adaptor protein inducing interferon $\beta$ (TRIF), with ensuing release of type I interferons and proinflammatory cytokines from innate immune cells like dendritic cells or macrophages [38]. MyD88 and TRIF were described to be involved in activation of autophagy by targeting Beclin-1 [39], emphasizing a direct connection between pathogen recognition and autophagy induction. Here, autophagy serves as an initial response but is additionally known to be a key component of the adaptive immune system.

The importance of Autophagy was also defined in the context of lymphocyte development and activity. The up-regulation of costimulatory signals released by APCs, sustains their migration to lymphoid organs. There, APCs and naive CD4+ $4^{+}$-cells encounter and interact with each other via detection of pathogen- peptides presented by MHC class II molecules [40], a process which is known as T-cell priming [41]. Lee and coworkers highlighted the significance of Atg 5 for antigen presentation by DCs, since deletion of Atg5 affected $\mathrm{CD}^{+}{ }^{+} \mathrm{T}$ cell priming upon viral infection [42]. After identification of their cognate peptide, naive $\mathrm{CD}^{+}{ }^{+} \mathrm{T}$ cells undergo cell division and differentiation into T helper 1 (TH1), T helper 2 (TH2), follicular T helpers, pro-inflammatory $\mathrm{T}$ helper 17 or regulatory $\mathrm{T}$ cells, depending on the milieu of cytokines [40]. All together these cells promote the growth and survival of T-lymphocytes, macrophages, B-cells and initiate inflammatory responses in order to induce a pathogen-specific answer by the immune system. The generation of Atg5-deficient mice resulted in a decrease of $\mathrm{T}$ - and B-lymphocyte production and impaired their proliferation $[43,44]$. Li et al. detected a stronger expression of LC3-GFP dots in TH2 cells, and assumed that autophagy takes place in TH2 more than in TH1 cells [45]. Being an important component of the autophagy cascade, mice lacking class III PI3K in a specific T-cell lineage exhibited not only major defects in the autophagic flux, but moreover showed disturbed T-cell regulation and developed later on an inflammatory wasting syndrome [46]. Importance of autophagy was furthermore revealed in the context of memory B-cells in mice showing increased levels of Atgs and autophagosome formation in first instance as a response against influenza virus infection [47]. Taken together, these findings support the conclusion that autophagy is strongly involved in the control of $\mathrm{CD}^{+}{ }^{+} \mathrm{T}$-cell homeostasis and is a constitutive part of the adaptive immune system.

\section{Anti- and proviral effects of Autophagy}

Autophagy comprises the elimination of intracellular pathogens in infected cells through lysosomal degradation. This process is commonly referred to as xenophagy $[4,48]$. Beside their regulatory role in autophagy, Atg proteins have been reported to be essential to mount an effective immune response to fight against viral infections [49]. The contribution of Atg proteins to cellular host defense was firstly depicted in the context of Sindbis virus infection and its regulation by Beclin 1 (also known as Atg6). Overexpression of the Bcl-2 interacting protein Beclin 1 led to an 
increased survival of Sindbis virus infected mice and protection against lethal encephalitis [50]. Reed et al, [51] illustrated the constitutive role of Beclin 1 in DCs upon respiratory syncytial virus infection. Mice with severe deficiencies in autophagy emanating from Beclin 1 haploinsufficiency, exhibited a reduced MHC class II expression and down- regulation of innate cytokine synthesis, resulting in serious lung pathology as a consequence. Further studies indicated a critical role of the Atg5-Atg12/ Atg16L1 complex for interferon- $\gamma$ mediated antiviral responses in norovirus-infected mice [52]. Moreover DCs, B- and epithelial cells expressing the Influenza A Matrix Protein 1 (M1) in fusion with LC3, demonstrated a 20-fold higher M1-specific MHC class II presentation to $\mathrm{CD} 4^{+} \mathrm{T}$ - cell clones than cells expressing $\mathrm{M} 1$ alone [35]. These outcomes emphasize the implication of autophagy in the host antiviral defense.

However, many viruses evolved different mechanisms to inhibit autophagy and therefore to ensure their survival and development in their host cells [Figure 4]. A very wellexploited example is the expression of Herpes Simplex Virus-1 (HSV-1) encoded inhibitory protein ICP34.5 which blocks the phosphorylation of the translation initiation factor $2 \alpha$ (eIF2 $\alpha$ ) by interacting with Beclin-1 and Protein-Kinase R (PKR) [53]. A further HSV-1 protein called US11 was also characterized to prevent autophagy through repression of PKR [54]. Further investigations represented the inhibitory role of the HCMV protein TRS1 on autophagy during the late phase of infection [55]. This effect could either be ascribed to the interaction of TRS1 with PKR [56] or as demonstrated by Chaumorcel et al. to binding of TRS1 to Beclin 1 [55]. First in vitro experiments reported interleukin-10 to be able to inhibit HCMV replication by blocking autophagy [57]. This study reinforces the existing dependence of HCMV on autophagy. In another case, infection of human lung epithelial cells with Influenza A virus (IAV) resulted in the accumulation of autophagosomes as a consequence of ceased fusion with lysosomes which could be attributed to viral Matrix Protein 2 (M2) [58]. Recent studies could show that this is due to interaction of LC3 protein with M2, which mimics the interaction of LC3 with its interaction motif, resulting in relocalization of LC3 at the plasma membrane. This was observed at time of virus budding of IAV infected cells and was assessed to be a critical step for viral replication [59]. Additionally, Human Immunodeficiency Virus (HIV) was described to block autophagosome formation through liberation of HIV tat and interleukin-10 [3,60]. HIV nef was proved to be at the origin of restrained autophagosome maturation [3,61]. In some cases, as for Hepatitis B virus (HBV), the impact of infection on autophagy stays elusive. First publications elucidated autophagy inducing activity of HBV protein X (HBx) through stimulation of a deathassociated protein kinase [62]. Although autophagosome formation and LC3 protein detection would favor the idea of HBVinduced autophagy, Liu and coworkers described HBx to impair lysosomal acidification and therefore to inhibit the autophagic degradation, having development of hepatocellular carcinoma as a consequence [63].

Disregarding prevention and repression of autophagy, viruses are even more able to induce and subvert autophagy for their own benefit [Figure 4]. Investigating this aspect, it was reported that Polio Virus (PV) infection enhances the formation of doublemembrane structures $[64,65]$ corresponding to LC3-positive vesicles [66]. These arranged membranes were suggested to originate from autophagy, for support of viral replication and release of virions [67]. Similar observations were made for another single stranded RNA virus, the Hepatitis C virus (HCV) $[68,69]$. Contrary to PV, autophagy is only required in the early stage of infection for translation and de novo synthesis of the HCV genome [70,71]. Viruses can supplementary use the autophagy machinery for their replication. Wen et al. indicated that a Kaposi' Sarcoma-associated Herpes virus (KSHV) infection causes an increase in the number of autophagic vesicles and LC3-lipidation, resulting in a reactivation and lytic replication of the virus, which was strongly down-regulated with autophagy inhibition [72]. Epstein-Barr virus (EBV) uses a similar mechanism, where

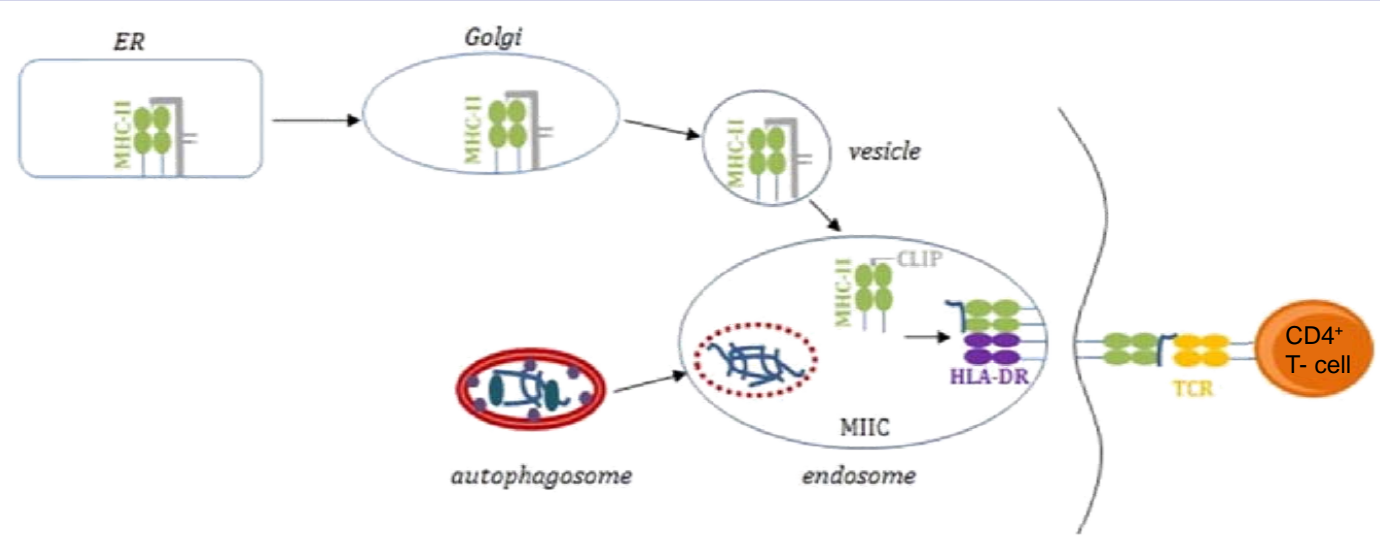

Figure 3: MHC class II presentation of autophagy processed antigens: MHC class II molecules and liassemble in the ER. The complex is then conducted from the Golgi to the MIIC through vesicle transport, where li is digested leaving CLIP. Simultaneously, auto phagosomes fuse with endosomes or MIIC for delivery and binding of antigens to MHC class II molecules, after HLA-DR mediated their dissociation from CLIP. Thus newly peptideloaded MHC class II complexes are transported to the cell surface and expose autophagy processed peptide epitopes to CD4 ${ }^{+}$-T cells to be recognized by their specific $\mathrm{T}$ cell receptors. 
virus propagation is also provided through autophagy vesicle transport [73]. On the other hand, during the latent phase of KSHV infection, autophagy is blocked in DCs which is presumably related to phosphorylation of Signal Transducer and Activator of Transcription 3 (STAT3), causing DC dysfunction and therefore immune evasion and virus persistence in the host [74]. The supportive role of autophagy was furthermore delineated in correlation with Dengue virus (DV) infection. An increased LC3-II expression, autophagosome formation and triggered autophagic flux in brain tissues of infected suckling mice led back to enhanced autophagy, probably to promote viral replication and pathogenesis [75]. The influence and dependence of pathogens on autophagy was additionally depicted in the context of Measles virus (MeV) infection [76]. MeV infection induces autophagy via different signaling pathways to limit the number of dying cells and improve formation of viral particles. Richetta, et al. demonstrated that infection of HeLa cells with an attenuated form of MeV elicits distinct waves of autophagy, involving in a first step the MeV cellular receptor CD46 and scaffold protein GOPC. After infection, viral replication and the expression of the non-structural measles virus protein $\mathrm{C}$, initiate the second wave of autophagy, which can be sustained through a third autophagy signal in infected cells, being the outcome of cell-cell fusion and formation of syncytia [76]. Viruses like Vaccinia Virus (VACV), seem to replicate independently of autophagy, but can still disrupt Autophagy $[77,78]$. Moloughney, et al. noticed a considerable LC3-lipidation after VACV infection, which was probably mediated through direct conjugation of Atg3 to Atg12. Despite these findings, neither autophagosome formation nor autophagic flux could be detected [77]. Nevertheless, previous investigations reported the capacity of VACV to replicate in autophagy-deficient cells as efficiently as in wild-type cells [79], indicating that virus may

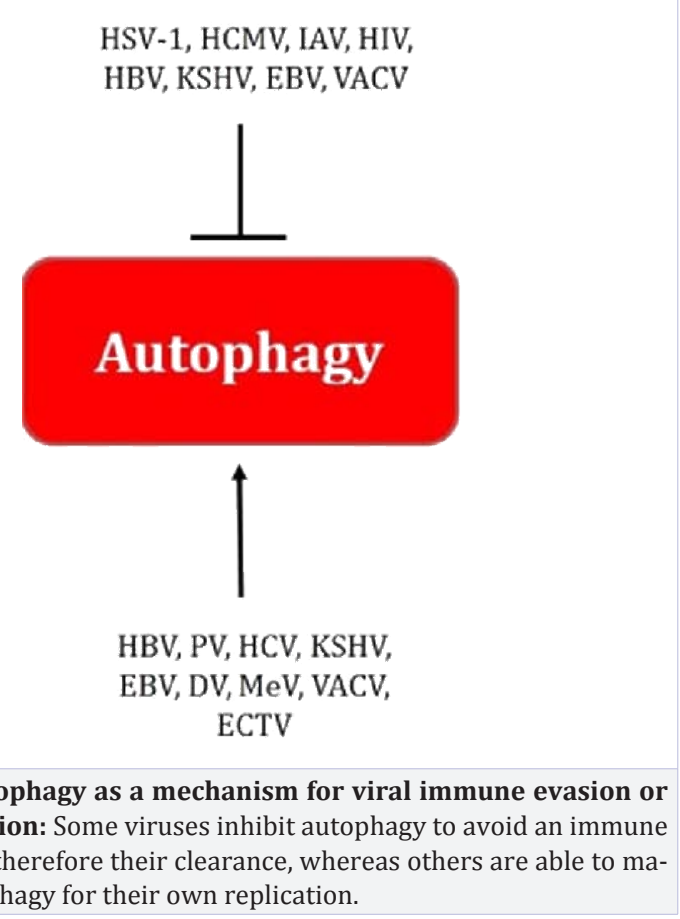
response and therefore nipulate autophagy for their own replication. not need autophagy for replication. Ectromelia virus (ECTV), which also belongs to the poxvirus family and is known to causes disease in mice, induces autophagy too [80], however studies regarding replication of ECTV and autophagy were not directed so far. Overall there are different strategies how viruses interact with the autophagy pathway.

\section{Conclusion}

In the last decades, autophagy has sparked huge interest and was shown to be involved in immunity. On one hand, autophagy participates in the cellular host defense through degradation of pathogens; but, on the other hand, impaired autophagy may result in neurological or immunological disorders and cancer. Additionally, during co-evolution with their mammalian host, many viruses have developed specific strategies to inhibit, manipulate or counteract the autophagy process. Acquiring deeper knowledge about the autophagy pathway, would grant further interest in how this machinery works by benefiting either the immune system or virus proliferation. These findings might be the basis for development of new viral therapeutics [81].

\section{References}

1. Klionsky DJ. Autophagy: from phenomenology to molecular understanding in less than a decade. Nat Rev Mol Cell Biol. 2007; 8(11): 931-937.

2. Kim HJ, Lee S, Jung JU. When autophagy meets viruses: a double-edged sword with functions in defense and offense. Semin Immunopathol. 2010; 32(4): 323-341.

3. Randow F, Münz C. Autophagy in the regulation of pathogen replication and adaptive immunity. Trends Immunol. 2012; 33(10): 475-487. doi: 10.1016/j.it.2012.06.003. Epub 2012 Jul 14.

4. Choi AM, Ryter SW, Levine B. Autophagy in human health and disease. N Engl J Med. 2013; 368(7): 651-662. doi: 10.1056/NEJMra1205406.

5. Ashford TP, Porter KR. Cytoplasmic components in hepatic cell lysosomes. J Cell Biol. 1962; 12: 198-202.

6. Klionsky DJ, Cregg JM, Dunn WA Jr, Emr SD, Sakai Y, Sandoval IV, et al. A unified nomenclature for yeast autophagy-related genes. Dev Cell. 2003; 5(4): 539-545.

7. Thumm M, Egner R, Koch B, Schlumpberger M, Straub M, Veenhuis $\mathrm{M}$, et al. Isolation of autophagocytosis mutants of Saccharomyces cerevisiae. FEBS Lett. 1994; 349(2): 275-280.

8. Tsukada M, Ohsumi Y. Isolation and characterization of autophagydefective mutants of Saccharomyces cerevisiae. FEBS Lett. 1993; 333(1-2): 169-174.

9. Ravikumar B, Sarkar S, Davies JE, Futter M, Garcia-Arencibia M, Green-Thompson ZW, et al. Regulation of mammalian autophagy in physiology and pathophysiology. Physiol Rev. 2010; 90: 1383-1435. doi: 10.1152/physrev.00030.2009.

10. Arsham AM, Neufeld TP. Thinking globally and acting locally with TOR. Curr Opin Cell Biol. 2006; 18(6): 589-597.

11. Bhaskar PT, Hay N. The two TORCs and Akt. Dev Cell. 2007; 12(4): 487-502.

12. Jacinto E, Loewith R, Schmidt A, Lin S, Rüegg MA, Hall A, et al. Mammalian TOR complex 2 controls the actin cytoskeleton and is rapamycin insensitive. Nat Cell Biol. 2004; 6(11): 1122-1128. 
13. Lee $\mathrm{CH}$, Inoki K, Guan KL. mTOR pathway as a target in tissue hypertrophy. Annu Rev Pharmacol Toxicol. 2007; 47: 443-467.

14. Sarbassov DD, Ali SM, Sabatini DM. Growing roles for the mTOR pathway. Curr Opin Cell Biol. 2005; 17(6): 596-603.

15. Pattingre S, Espert L, Biard-Piechaczyk M, Codogno P. Regulation of macroautophagy by mTOR and Beclin 1 complexes. Biochimie. 2008; 90(2): 313-323.

16. Ganley IG, Lam du H, Wang J, Ding X, Chen S, Jiang X. ULK1.ATG13. FIP200 complex mediates mTOR signaling and is essential for autophagy. J Biol Chem. 2009; 284(18): 12297-12305. doi: 10.1074/ jbc.M900573200.

17. Hosokawa N, Hara T, Kaizuka T, Kishi C, Takamura A, Miura Y, et al. Nutrient-dependent mTORC1 association with the ULK1-Atg13FIP200 complex required for autophagy. Mol Biol Cell. 2009; 20(7): 1981-1991. doi: 10.1091/mbc.E08-12-1248..

18. Jung CH, Jun CB, Ro SH, Kim YM, Otto NM, Cao J, et al.ULK-Atg13-FIP200 complexes mediate mTOR signaling to the autophagy machinery. Mol Biol Cell. 2009; 20(7): 1992-2003. doi: 10.1091/mbc.E08-12-1249.

19. Mercer CA, Kaliappan A, Dennis PB. A novel, human Atg13 binding protein, Atg101, interacts with ULK1 and is essential for macroautophagy. Autophagy. 2009; 5(5): 649-662.

20. Hosokawa N, Sasaki T, Iemura S, Natsume T, Hara T, Mizushima N. Atg101, a novel mammalian autophagy protein interacting with Atg13. Autophagy. 2009; 5(7): 973-979.

21. Itakura E, Kishi C, Inoue K, Mizushima N. Beclin 1 forms two distinct phosphatidylinositol 3-kinase complexes with mammalian Atg14 and UVRAG. Mol Biol Cell. 2008; 19(12): 5360-5372. doi: 10.1091/mbc. E08-01-0080.

22. Sun Q, Fan W, Chen K, Ding X, Chen S, Zhong Q. Identification of Barkor as a mammalian autophagy-specific factor for Beclin 1 and class III phosphatidylinositol 3-kinase. Proc Natl Acad Sci U S A. 2008; 105(49): 19211-19216. doi: 10.1073/pnas.0810452105.

23. Dengjel J, Schoor O, Fischer R, Reich M, Kraus M, Müller M, et al. Autophagy promotes MHC class II presentation of peptides from intracellular source proteins. Proc Natl Acad Sci U S A. 2005; 102(22): 7922-7927.

24. Nimmerjahn F, Milosevic S, Behrends U, Jaffee EM, Pardoll DM, Bornkamm GW, et al. Major histocompatibility complex class IIrestricted presentation of a cytosolic antigen by autophagy. Eur J Immunol. 2003; 33(5): 1250-1259.

25. Paludan C, Schmid D, Landthaler M, Vockerodt M, Kube D, Tuschl T, et al. Endogenous MHC class II processing of a viral nuclear antigen after autophagy. Science. 2005; 307(5709): 593-596.

26. Donaldson JG, Williams DB. Intracellular assembly and trafficking of MHC class I molecules. Traffic. 2009; 10(12): 1745-1752. doi: 10.1111/j.1600-0854.2009.00979.

27. English L, Chemali M, Duron J, Rondeau C, Laplante A, Gingras D, et al. Autophagy enhances the presentation of endogenous viral antigens on MHC class I molecules during HSV-1 infection. Nat Immunol. 2009; 10(5): 480-487. doi: 10.1038/ni.1720.

28. Tey SK, Khanna R. Autophagy mediates transporter associated with antigen processing-independent presentation of viral epitopes through MHC class I pathway. Blood. 2012; 120(5): 994-1004. doi: 10.1182/blood-2012-01-402404.

29. Bevan MJ. Cross-priming. Nat Immunol. 2006; 7(4): 363-365.
30. Li Y, Wang LX, Yang G, Hao F, Urba WJ, Hu HM. Efficient crosspresentation depends on autophagy in tumor cells. Cancer Res. 2008; 68(17): 6889-6895. doi: 10.1158/0008-5472.CAN-08-0161.

31. Neefjes J, Jongsma ML, Paul P, Bakke O. Towards a systems understanding of MHC class I and MHC class II antigen presentation. Nat Rev Immunol. 2011; 11(12): 823-836. doi: 10.1038/nri3084.

32. Vyas JM, Van der Veen AG, Ploegh HL. The known unknowns of antigen processing and presentation. Nat Rev Immunol. 2008; 8(8): 607-618. doi: $10.1038 /$ nri2368.

33. Crotzer VL, Blum JS. Autophagy and adaptive immunity. Immunology. 2010; 131(1): 9-17. doi: 10.1111/j.1365-2567.2010.03321.

34. Dongre AR, Kovats $\mathrm{S}$, deRoos $\mathrm{P}$, McCormack AL, Nakagawa $\mathrm{T}$, Paharkova-Vatchkova $\mathrm{V}$, et al. In vivo MHC class II presentation of cytosolic proteins revealed by rapid automated tandem mass spectrometry and functional analyses. Eur J Immunol. 2001; 31(5): $1485-1494$

35. Schmid D, Pypaert M, Munz C. Antigen-loading compartments for major histocompatibility complex class II molecules continuously receive input from autophagosomes. Immunity. 2007; 26(1): 79-92.

36. Berg TO, Fengsrud M, Strømhaug PE, Berg T, Seglen PO. Isolation and characterization of rat liver amphisomes. Evidence for fusion of autophagosomes with both early and late endosomes. J Biol Chem. 1998; 273(34): 21883-21892.

37. Kondylis V, van Nispen Tot Pannerden HE, van Dijk S, Ten Broeke T, Wubbolts R, Geerts WJ, et al. Endosome-mediated autophagy: an unconventional MIIC-driven autophagic pathway operational in dendritic cells. Autophagy. 2013; 9(6): 861-880. doi: 10.4161/ auto. 24111 .

38. Akira S, Takeda K. Toll-like receptor signalling. Nat Rev Immunol. 2004; 4(7): 499-511.

39. Shi CS, Kehrl JH. MyD88 and Trif target Beclin 1 to trigger autophagy in macrophages. J Biol Chem. 2008; 283(48): 33175-33182. doi: 10.1074/jbc.M804478200.

40. Swain SL, McKinstry KK, Strutt TM. Expanding roles for CD4+ $\mathrm{T}$ cells in immunity to viruses. Nat Rev Immunol. 2012; 12(2): 136-148. doi: 10.1038/nri3152.

41. Janeway CA Jr. The priming of helper T cells. Semin Immunol. 1989; $1(1): 13-20$.

42. Lee HK, Mattei LM, Steinberg BE, Alberts P, Lee YH, Chervonsky A, et al. In vivo requirement for Atg5 in antigen presentation by dendritic cells. Immunity. 2010; 32(2): 227-239. doi: 10.1016/j.immuni.2009.12.006.

43. Miller BC, Zhao Z, Stephenson LM, Cadwell K, Pua HH, Lee HK, et al. The autophagy gene ATG5 plays an essential role in B lymphocyte development. Autophagy. 2008; 4(3): 309-314.

44. Pua HH, Dzhagalov I, Chuck M, Mizushima N, He YW. A critical role for the autophagy gene Atg5 in T cell survival and proliferation. J Exp Med. 2007; 204(1): 25-31.

45. Li C, Capan E, Zhao Y, Zhao J, Stolz D, Watkins SC, et al. Autophagy is induced in CD4+ $\mathrm{T}$ cells and important for the growth factorwithdrawal cell death. J Immunol. 2006; 177(8): 5163-5168.

46. Parekh VV, Wu L, Boyd KL, Williams JA, Gaddy JA, Olivares-Villagómez D, et al. Impaired autophagy, defective T cell homeostasis, and a wasting syndrome in mice with a T cell-specific deletion of Vps34. J Immunol. 2013; 190(10): 5086-5101. doi: 10.4049/jimmunol.1202071.

47. Chen M, Hong MJ, Sun H, Wang L, Shi X, Gilbert BE, et al. Essential role 
for autophagy in the maintenance of immunological memory against influenza infection. Nat Med. 2014; 20(5): 503-510. doi: 10.1038/ nm.3521.

48. Levine B, Mizushima N, Virgin HW. Autophagy in immunity and inflammation. Nature. 2011; 469(7330): 323-335. doi: 10.1038/ nature09782.

49. Virgin HW, Levine B. Autophagy genes in immunity. Nat Immunol. 2009; 10(5): 461-470. doi: 10.1038/ni.1726.

50. Liang XH, Kleeman LK, Jiang HH, Gordon G, Goldman JE, Berry G, et al Protection against fatal Sindbis virus encephalitis by beclin, a novel Bcl-2-interacting protein. J Virol. 1998; 72(11): 8586-8596.

51. Reed M, Morris SH, Jang S, Mukherjee S, Yue Z, Lukacs NW. Autophagyinducing protein beclin-1 in dendritic cells regulates CD4 $\mathrm{T}$ cell responses and disease severity during respiratory syncytial virus infection. J Immunol. 2013; 191(5): 2526-2537. doi: 10.4049/ jimmunol.1300477.

52. Hwang S, Maloney NS, Bruinsma MW, Goel G, Duan E, Zhang L, et al. Nondegradative role of Atg5-Atg12/ Atg16L1 autophagy protein complex in antiviral activity of interferon gamma. Cell Host Microbe. 2012; 11(4): 397-409. doi: 10.1016/j.chom.2012.03.002.

53. Tallóczy Z, Jiang W, Virgin HW 4th, Leib DA, Scheuner D, Kaufman RJ, et al. Regulation of starvation- and virus-induced autophagy by the eIF2alpha kinase signaling pathway. Proc Natl Acad Sci U S A. 2002; 99(1): 190-195.

54. Lussignol M, Queval C, Bernet-Camard MF, Cotte-Laffitte J, Beau I, Codogno $\mathrm{P}$, et al. The herpes simplex virus 1 Us11 protein inhibits autophagy through its interaction with the protein kinase PKR. J Virol. 2013; 87(2): 859-871. doi: 10.1128/JVI.01158-12.

55. Chaumorcel M, Lussignol M, Mouna L, Cavignac Y, Fahie K, CotteLaffitte J, et al. The human cytomegalovirus protein TRS1 inhibits autophagy via its interaction with Beclin 1. J Virol. 2012; 86(5): 25712584. doi: 10.1128/JVI.05746-11.

56. Hakki M, Marshall EE, De Niro KL, Geballe AP. Binding and nuclear relocalization of protein kinase $\mathrm{R}$ by human cytomegalovirus TRS1. J Virol. 2006; 80(23): 11817-11826.

57. Wang L, Zhang H, Qian J, Wang K, Zhu J. Interleukin-10 blocks in vitro replication of human cytomegalovirus by inhibiting the virus-induced autophagy in MRC5 cells. Biochem Biophys Res Commun. 2014; 448(4): 448-453. doi: 10.1016/j.bbrc.2014.04.120.

58. Gannagé M, Dormann D, Albrecht R, Dengjel J, Torossi T, Rämer PC, et al. Matrix protein 2 of influenza A virus blocks autophagosome fusion with lysosomes. Cell Host Microbe. 2009; 6(4): 367-380. doi: 10.1016/j.chom.2009.09.005.

59. Beale R, Wise H, Stuart A, Ravenhill BJ, Digard P, Randow F. A LC3interacting motif in the influenza A virus M2 protein is required to subvert autophagy and maintain virion stability. Cell Host Microbe. 2014; 15(2): 239-247. doi: 10.1016/j.chom.2014.01.006.

60. Van Grol J, Subauste C, Andrade RM, Fujinaga K, Nelson J, Subauste CS. HIV-1 inhibits autophagy in bystander macrophage/monocytic cells through Src-Akt and STAT3. PLoS One. 2010; 5(7): e11733. doi: 10.1371/journal.pone.0011733.

61. Kyei GB, Dinkins C, Davis AS, Roberts E, Singh SB, Dong C, et al. Autophagy pathway intersects with HIV-1 biosynthesis and regulates viral yields in macrophages. J Cell Biol. 2009; 186(2): 255-268. doi: $10.1083 /$ jcb.200903070.

62.Zhang HT, Chen GG, Hu BG, Zhang ZY, Yun JP, He ML, et al. Hepatitis
$B$ virus x protein induces autophagy via activating death-associated protein kinase. J Viral Hepat. 2014; 21(9): 642-649. doi: 10.1111/ jvh.12191.

63. Liu B, Fang M, Hu Y, Huang B, Li N, Chang C, et al. Hepatitis B virus $\mathrm{X}$ protein inhibits autophagic degradation by impairing lysosomal maturation. Autophagy. 2014; 10(3): 416-430. doi: 10.4161/ auto. 27286 .

64. Suhy DA, Giddings TH Jr, Kirkegaard K. Remodeling the endoplasmic reticulum by poliovirus infection and by individual viral proteins: an autophagy-like origin for virus-induced vesicles. J Virol. 2000; 74(19): 8953-8965.

65. Schlegel A, Giddings TH Jr, Ladinsky MS, Kirkegaard K. Cellular origin and ultrastructure of membranes induced during poliovirus infection. J Virol. 1996; 70(10): 6576-6588.

66. Jackson WT, Giddings TH Jr, Taylor MP, Mulinyawe S, Rabinovitch M, Kopito RR, et al. Subversion of cellular autophagosomal machinery by RNA viruses. PLoS Biol. 2005; 3(5): e156.

67.Lin LT, Dawson PW, Richardson CD. Viral interactions with macroautophagy: a double-edged sword. Virology. 2010; 402: 1-10. doi: 10.1016/j.virol.2010.03.026.

68. Sir D, Kuo CF, Tian Y, Liu HM, Huang EJ, Jung JU, et al. Replication of hepatitis $\mathrm{C}$ virus RNA on autophagosomal membranes. J Biol Chem. 2012; 287(22): 18036-18043. doi: 10.1074/jbc.M111.320085.

69. Ferraris P, Blanchard E, Roingeard P. Ultrastructural and biochemical analyses of hepatitis C virus-associated host cell membranes. J Gen Virol. 2010; 91(9): 2230-2237. doi: 10.1099/vir.0.022186-0.

70. Dreux M, Gastaminza P, Wieland SF, Chisari FV. The autophagy machinery is required to initiate hepatitis $\mathrm{C}$ virus replication. Proc Natl Acad Sci U S A. 2009; 106(33): 14046-14051. doi: 10.1073/ pnas.0907344106.

71. Dong X, Levine B. Autophagy and viruses: adversaries or allies? J Innate Immun. 2013; 5(5): 480-493. doi: 10.1159/000346388.

72. Wen HJ, Yang Z, Zhou Y, Wood C. Enhancement of autophagy during lytic replication by the Kaposi's sarcoma-associated herpesvirus replication and transcription activator. J Virol. 2010; 84(15): 74487458. doi: 10.1128/JVI.00024-10.

73. Granato M, Santarelli R, Farina A, Gonnella R, Lotti LV, Faggioni A, et al. Epstein-barr virus blocks the autophagic flux and appropriates the autophagic machinery to enhance viral replication. J Virol. 2014; 88(21): 12715-12726. doi: 10.1128/JVI.02199-14.

74. Santarelli R, Gonnella R, Di Giovenale G, Cuomo L, Capobianchi A, Granato M, et al. STAT3 activation by KSHV correlates with IL-10, IL-6 and IL-23 release and an autophagic block in dendritic cells. Sci Rep. 2014; 4: 4241. doi: 10.1038/srep04241.

75. Lee YR, Hu HY, Kuo SH, Lei HY, Lin YS, Yeh TM, et al. Dengue virus infection induces autophagy: an in vivo study. J Biomed Sci. 2013; 20: 65. doi: 10.1186/1423-0127-20-65.

76. Richetta C, Grégoire IP, Verlhac P, Azocar O, Baguet J, Flacher M, et al. Sustained autophagy contributes to measles virus infectivity. PLoS Pathog. 2013; 9(9): e1003599. doi: 10.1371/journal.ppat.1003599.

77. Moloughney JG, Monken CE, Tao H, Zhang H, Thomas JD, Lattime EC, et al. Vaccinia virus leads to ATG12-ATG3 conjugation and deficiency in autophagosome formation. Autophagy. 2011; 79(12): 1434-1447.

78. Verardi PH, Titong A, Hagen CJ. A vaccinia virus renaissance: new vaccine and immunotherapeutic uses after smallpox eradication. Hum Vaccin Immunother. 2012; 8(7): 961-970. doi: 10.4161/hv.21080. 
79. Zhang H, Monken CE, Zhang Y, Lenard J, Mizushima N, Lattime EC, et al. Cellular autophagy machinery is not required for vaccinia virus replication and maturation. Autophagy. 2006; 2(2): 91-95.

80. Martyniszyn L, Szulc-Dąbrowska L, Boratyńska-Jasińska A, Niemiałtowski M. Increased formation of autophagosomes in ectromelia virus-infected primary culture of murine bone marrowderived macrophages. Acta Virol. 2013; 57(4): 467-470.

81. Rubinsztein DC, Gestwicki JE, Murphy LO, Klionsky DJ. Potential therapeutic applications of autophagy. Nat Rev Drug Discov. 2007; 6(4): 304-312. 